\title{
Graphite-Polyurethane Composite Electrode Modified with Molecularly Imprinted Polymer for Determination of Diclofenac
}

\author{
Abigail V. Pereira, ${ }^{a}$ Priscila Cervini, ${ }^{\circledR a}$ Victor A. G. Rivera ${ }^{b}$ and Éder T. G. Cavalheiro ${ }^{\circledR} * a$ \\ ${ }^{a}$ Instituto de Química de São Carlos, Universidade de São Paulo, 13566-590 São Carlos-SP, Brazil \\ ${ }^{b}$ Facultad de Ciencias Físicas, Universidad Nacional Mayor de San Marcos, \\ Av. Carlos Germán Amezaga No. 375, PO Box 1558 Lima, Peru
}

\begin{abstract}
A molecularly imprinted polymer (MIP) was prepared using the anti-inflammatory diclofenac (DCF) as a template. A non-imprinted polymer (NIP) was also prepared as a control. These MIP and NIP were characterized by scanning electron microscopy (SEM), transmission electron microscopy (TEM) and Brunauer-Emmett-Teller (BET), revealing a higher porosity in the first. Then both were used in the modification of graphite-polyurethane composites electrodes (GPUE). Differential pulse anodic stripping voltammetry was used for DCF determination at GPUE-MIP-DCF containing $2.5 \%(\mathrm{~m} / \mathrm{m})$ of the modifier in perchloric acid, $\mathrm{pH}=2.0$, after previously optimized conditions such as $300 \mathrm{~s}$ of accumulation time, $+0.2 \mathrm{~V}$ accumulation potential ( $v s$. SCE (saturated calomel electrode)), $50 \mathrm{mV}$ pulse amplitude and $10 \mathrm{mV} \mathrm{s}^{-1}$ scan rate. A linear dynamic range from 0.010 to $0.20 \mu \mathrm{mol} \mathrm{L}-1$ and a limit of detection (LOD) of $0.99 \mathrm{nmol} \mathrm{L}^{-1}$ were found, using GPUE-2.5-MIP-DCF. DCF was determined in commercial pharmaceutical formulations and in synthetic urine samples, with recoveries between 101 and $102 \%(n=3)$ and $101 \%(n=3)$, respectively. The results agreed with the reference high-performance liquid chromatography (HPLC) within 95\% confidence level, according to Student's $t$-test. Interference from meclofenamic and mefenamic acids, which are structurally similar to DCF, was also evaluated. Interferences could not be totally avoided, but MIPs presented a considerable ability in discriminating the voltammetric response for DFC, despite the close structural similarity with the interferents.
\end{abstract}

Keywords: electrochemical sensor, differential pulse anodic stripping voltammetry, selectivity

\section{Introduction}

Molecularly imprinted polymers (MIPs) consist of a rigid three-dimensional polymeric structure surrounding/ around a template molecule that could act in a similar way of the antibody. The result is a structure able to perform molecular recognition conferring selectivity for the electroanalytical detectors. ${ }^{1}$

MIPs are conventionally prepared by a method known as bulk polymerization, where the reaction is carried out in a homogeneous system. This reaction is conducted in sealed bottles containing monomer, analyte, solvent, cross-linking reagent and radical initiator. The choice of these reagents is dictated by the nature of the analyte's interaction with the monomer. The reaction takes place in the absence of oxygen under $\mathrm{N}_{2}$ or Ar flow and induced with heating and/ or ultraviolet (UV) radiation. ${ }^{2}$

The template molecule is linked to the terminal polymeric

*e-mail: cavalheiro@iqsc.usp.br

Editor handled this article: Rodrigo A. A. Muñoz (Associated) spots that contain functional groups able to interact with the template by covalent or attractive forces. Finally, the resulting polymeric solid is ground, sieved and subjected to a wash, in which, the template can be removed by solvent extraction generating a cavity with its shape and size in which other template molecule can be bonded during the pre-concentration/analysis, resulting in a selective interaction of the MIP with the template. ${ }^{3-5}$ The non-imprinting polymer (NIP) does not have the template molecule in its structure.

MIPs present several advantages such as chemical, mechanical and thermal stability, control in the orientation and density of molecular imprinting sites on the surface of the devices, providing fast and accurate detection of the analyte. ${ }^{6,7}$

A detailed description of MIPs as electrode modifiers and how they work is already presented in literature. ${ }^{8}$

Sodium diclofenac (sodium;2-[2-(2,6-dichloroanilino) phenyl]acetate, DCF, Figure 1) is a non-steroidal antiinflammatory drug (NSAID), with analgesic, antipyretic and anti-inflammatory activities. ${ }^{9}$ The structural formula of sodium diclofenac is represented in Figure 1. 
<smiles>O=C([O-])Cc1ccccc1Nc1c(Cl)cccc1Cl</smiles>

Figure 1. Structural formula of sodium diclofenac.

The drug is indicated for the treatment of several inflammatory processes, such as rheumatoid arthritis, osteoarthrosis, ankylosing spondylitis, renal colic, minor surgeries, trauma and dysmenorrhea, ${ }^{10}$ being one of the most popular anti-inflammatory drugs used all around the word.

According to pharmacokinetic studies, approximately $60 \%$ of the administered doses are excreted in the urine as the glucuronic conjugate of the molecule and as metabolites, and less than $1 \%$ is excreted as unchanged substance. The rest of the dose is eliminated as metabolites through bile and feces. ${ }^{11}$

The contamination of water and soil by drugs has also increasing concern regarding impact on human health and the environmental issues even at low concentrations. ${ }^{12-14}$ The development of more efficient water treatment methods, for example, has in common the focus on drug degradation, including diclofenac as one of the most worrisome due to its high consumption. ${ }^{14-16}$

Most common analytical methods used to determine diclofenac involves gas chromatography, ${ }^{17}$ capillary electrophoresis ${ }^{18}$ and high-performance liquid chromatography (HPLC). ${ }^{19,20}$ Examples of voltammetric procedures for determination of DCF in urine and pharmaceutical formulations include doped diamond boron electrodes, ${ }^{21,22}$ pyrolytic graphite, ${ }^{23}$ glassy carbon modified with functionalized graphene oxide,${ }^{24}$ glassy carbon modified with multi walled carbon nanotube, ${ }^{25}$ ionic liquid/ cobalt hexacyanoferrate nanoparticle modified multi-walled carbon nanotubes nanocomposite paste electrode ${ }^{26}$ and a graphene nanoribbon modified screen printed electrode. ${ }^{27}$

Although there are several papers using MIPs for sample preparation in chromatographic procedures, few papers reported the use of molecularly imprinting polymers having DCF as a template in voltammetric procedures involving composite electrodes modified with such modifier.

Papers using MIP as composite electrode modifier in the determination of diclofenac include Blanco-López et al. ${ }^{28}$ in which the composite electrodes used were polytetrafluoroethylene-graphite, epoxy-graphite and epoxy-carbon black. In other work, Blanco-López et al. ${ }^{29}$ determined diclofenac using MIP, however, the modifier was deposited onto the surface of a glassy carbon electrode
(GCE). Al-Bayati and Al-Safi ${ }^{30}$ prepared two types of electrodes containing MIPs varying the monomer, however, potentiometry was used. Mostafavi et al. ${ }^{31}$ prepared MIP for modification of carbon paste electrodes. The selectivity of the investigated sensor was evaluated by its use for determination of DCF in binary solutions containing $\mathrm{DCF} / \mathrm{glucose}$, urea or ascorbic acid. Seguro et al..$^{32}$ prepared an MIP on a screen-printed carbon electrode in the determination of DCF in spiked water samples. The MIP sensor showed adequate selectivity and satisfactory detection and quantification limits. Metal-organic frameworks (MOF) Zr-MOF/GCE-MIP were prepared by Malekzadeh et al. ${ }^{33}$ with good sensitivity, selectivity and reproducibility for the determination of DCF in pharmaceutical commercial samples.

In the present work, a modification of a graphite polyurethane electrode with an MIP containing DCF as template for its determination in pharmaceutical formulations and synthetic urine samples was evaluated. The selectivity of the resulting device was also evaluated regarding molecules with similar structure and functional groups.

\section{Experimental}

\section{Experimental apparatus}

The resulting MIP and NIP samples were analyzed by scanning electron microscopy (SEM) in order to evaluate their morphological features using a 440 LEO microscope (Zeiss, Oxford, UK) with detector operating with electron beam of $20 \mathrm{kV}$. The samples were recovered with a gold layer in a Baltec MED 020 coating system (Zevenhuizen,The Netherlands).

The MIP and NIP morphologies were investigated by transmission electron microscopy (TEM) using a Philips CM-120 microscope (Amsterdan, The Netherlands) with an electron beam of 31-380 kV. The samples were suspended in isopropanol (Tédia, Rio de Janeiro, Brazil). One drop of the suspension was placed in a copper grid (200 mesh, Electron Microscopy Sciences, Hatfield, USA) covered with carbon thin film.

Changes in the surface area for MIP and NIP were evaluated using Brunauer-Emmett-Teller (BET) measurements performed from physical $\mathrm{N}_{2}$ adsorption in a Micromeritics ASAP 2020 V3 (Oxford, UK) equipment.

The voltammetric measurements were performed using a $\mu$-AUTOLAB type III potentiostat/galvanostat (Ecochemie, São Paulo, Brazil) coupled to a microcomputer and controlled by GPES 4.9 (Ecochemie) software. The counter electrode was a platinum foil with total area of $1 \mathrm{~cm}^{2}$. A saturated calomel electrode ( $\mathrm{SCE}, \mathrm{Hg} / \mathrm{Hg}_{2} \mathrm{Cl}_{2}$ ) was 
used as the reference electrode. The graphite-polyurethane composite electrode (GPUE), GPUE-MIP-DCF and GPUENIP were used as the working electrodes.

Liquid chromatograms were obtained using a Shimadzu LC-10AD UP (São Paulo, Brazil) chromatograph equipped with an SPD-10A UV-UP detector and an LC-6AD pump, controlled using Class-VP software. A C-18 column $(15 \mathrm{~cm} \times 4.6 \mathrm{~cm} \times 5 \mathrm{~mm})$ was maintained at room temperature and the mobile phase was a mixture of acetonitrile (ACN) and water $(6: 4, v / v)$, pumped at a flow rate of $0.6 \mathrm{~mL} \mathrm{~min}{ }^{-1}$. The detector wavelength was set at $278 \mathrm{~nm}$.

\section{Reagents and solutions}

All solutions were prepared using water purified in a Barnstead EASYPure ${ }^{\circledR}$ RoDi system (Model D13321, Thermo Scientific, resistivity $>18 \mathrm{M} \Omega \mathrm{cm}$, São Paulo, Brazil). All reagents were of analytical grade and used without further purification.

The reagents used in the synthesis of MIP were methacrylic acid (MAA, 95\%, Acrös Organics, Jersey, USA), azobisisobutyronitrile (AIBN, 95\%, Acrös Organics, Jersey, USA), ethyleneglycol dimetacrylate (EGDMA, 98\%, Polysciencis, Inc., Warrington, UK), acetonitrile (ACN, Tédia, Rio de Janeiro, Brazil), methanol (Tédia, Rio de Janeiro, Brazil) and acetic acid (Mallinckrodt, São Paulo, Brazil).

The DCF (Sigma-Aldrich, Campinas, Brazil) stock solutions were prepared daily by dissolution of the reagent in ACN. Working solutions were prepared by adding aliquots in phosphate buffer with $10 \% \mathrm{ACN}$ or in perchloric acid (Mallinckrodt, São Paulo, Brazil) with 10\% ACN.

Commercial pharmaceutical formulations containing diclofenac as active agent from samples of three pharmaceutical companies were purchased in local drugstores.

Synthesis and characterization of the molecularly imprinted (and non-imprinted) polymer

The MIP-DCF synthesis was made using the conventional bulk polymerization approach, as described by Tarley et al..$^{34} \mathrm{~A}$ polymer without molecular imprinting (NIP) was also synthesized in the same way as the MIP, but without adding the template during the synthesis.

Briefly, $2.48 \mathrm{mmol}$ of MAA monomer and $12.6 \mathrm{mmol}$ of crosslinking agent (EGDMA) were added to a glass ampoule, followed by $0.50 \mathrm{mmol}$ of DCF template and $0.19 \mathrm{mmol}$ of AIBN initiator and the mixture was dissolved in $4.20 \mathrm{~mL}$ of ACN. The ampoule was sealed with a rubber septum and purged with nitrogen for 30 min with the help of a hypodermic needle. The ampoule was then left in a thermostatically controlled water bath (Model MA-184, Marconi, Rio de Janeiro, Brazil) at $50{ }^{\circ} \mathrm{C}$ for $24 \mathrm{~h}$.

After the synthesis of the MIP, DCF was removed by washing the material with methanol/acetic acid $(1: 9, \mathrm{v} / \mathrm{v})$ in a Soxhlet system during $10 \mathrm{~h}$. The resulting polymer was grinded in a mortar and sieved to obtain MIPs with a particle size smaller than $150 \mu \mathrm{m}$, which was used in the fabrication of the electrodes.

A polymer without molecular imprinting (NIP) was also synthesized and treated in the same way as the MIP, but without adding the template molecule during the synthesis.

Preparation of the modified graphite-polyurethane composite electrode

The best composition of the unmodified GPUE was previously established as $60 \%(\mathrm{~m} / \mathrm{m})$ graphite and $40 \%(\mathrm{~m} / \mathrm{m})$ polyurethane $(\mathrm{PU}){ }^{35}$ Electrodes modified with 2.5, 5.0, 7.5 and $10 \%(\mathrm{~m} / \mathrm{m})$ of MIP were prepared by replacing equal parts of graphite and PU by the modifier. ${ }^{22}$ The mixtures were homogenized for $5 \mathrm{~min}$ in a glass mortar, extruded as $3 \mathrm{~mm}$ diameter rods in a manual press and allowed to cure for $24 \mathrm{~h}$ at room temperature. After that, $1.0 \mathrm{~cm}$ longer the rods were cut and connected to copper wires with silver epoxy (EPO-TEK 410E, Epoxy Technology, São Paulo, Brazil). After 24 h, the composite/ copper wire assemblies were inserted into glass tubes (6 $\mathrm{mm}$ internal diameter, $9 \mathrm{~cm}$ length), which were filled with epoxy resin (Silaex SQ 3024, São Paulo, Brazil) and allowed to cure for $24 \mathrm{~h}$. Mechanical abrasion with 500 grit sandpaper was performed to remove excess epoxy resin from the surface and expose the composite. Finally, the electrode was sonicated in isopropyl alcohol for $5 \mathrm{~min}$ and then in water for $5 \mathrm{~min}$ before each measurements set.

\section{Procedures}

The best electrode composition among 2.5, 5.0, 7.5 and $10 \%(\mathrm{~m} / \mathrm{m})$ of MIP was determined by differential pulse anodic stripping voltammetry (DPASV) using $10 \mathrm{mV} \mathrm{s}^{-1}$ scan rate, $50 \mathrm{mV}$ pulse amplitude, $300 \mathrm{~s}$ accumulation time $\left(\mathrm{t}_{\text {acc }}\right)$ and $0.20 \mathrm{~V}$ accumulation potential $\left(\mathrm{E}_{\mathrm{acc}}\right)$, in $25 \mathrm{mmol} \mathrm{L}^{-1}$ perchloric acid conditional $\mathrm{pH} 2.0$ $\left(\mathrm{C}_{\mathrm{H}+}=0.010 \mathrm{~mol} \mathrm{~L}^{-1}\right)$, with $10 \% \mathrm{ACN}$.

To optimize the accumulation potential, $50 \mathrm{mV}$ amplitude and $10 \mathrm{mV} \mathrm{s}^{-1}$ scan rate were used at GPUE-2.5-MIP-DCF. The pre concentration time of $60 \mathrm{~s}$ was fixed and voltammograms were obtained with values of $0.0,0.1,0.2,0.3,0.4$ and $0.5 \mathrm{~V}$ ( vs. SCE) 
accumulation potential, with surface renewal between each measurement. Voltammograms are presented as Supplementary Information (SI section, Figure S1). After that, using the optimized accumulation potential previously, voltammograms were obtained with pre concentration time of $0 ; 60 ; 120 ; 180 ; 240 ; 300 ; 360$ and 480 s (Figure S2, SI section).

The optimization of the pulse amplitude (a) and scan rate (v) was made using a factorial planning $2^{\mathrm{n}}$, being $\mathrm{n}=$ number of variables, with values of $\mathrm{v}=10$ and $25 \mathrm{mV} \mathrm{s}^{-1}$ and $\mathrm{a}=25$ and $50 \mathrm{mV}$, totalizing four experiments (Figure S3, SI section), using $20 \mu \mathrm{mol} \mathrm{L}^{-1}$ DCF, in $25 \mathrm{mmol} \mathrm{L}^{-1}$ perchloric acid, with $10 \% \mathrm{ACN}$, $\mathrm{C}_{\mathrm{H}+}=0.010 \mathrm{~mol} \mathrm{~L}^{-1}$.

Then, comparative analytical curves were obtained with optimized conditions at GPUE-2.5-MIP-DCF, GPUE-2.5-NIP and unmodified GPUE with DCF concentrations from 0.01 to $1.0 \mu \mathrm{mol} \mathrm{L} \mathrm{L}^{-1}$, in $25 \mathrm{mmol} \mathrm{L}^{-1}$ perchloric acid $\mathrm{pH} 2.0$, with $10 \%$ ACN.

Determination of DCF in pharmaceutical formulations by the standard addition method

In accordance with the Brazilian Pharmacopeia, ${ }^{36}$ 20 tablets of each pharmaceutical formulations were accurately weighed $( \pm 0.1 \mathrm{mg})$ and grinded. Portions of each powdered sample equivalent to $50 \mathrm{mg}$ of DCF (based on the label) were dissolved in $100 \mathrm{~mL} \mathrm{ACN}$ in order to obtain $100 \mu \mathrm{mol} \mathrm{L}{ }^{-1}$ DCF solutions. The solutions were sonicated for $20 \mathrm{~min}$ to ensure complete dissolution.

\section{Comparative method}

The comparative method employed was that proposed by Kirim et al. ${ }^{37}$ based in HPLC. For this, a solution of $1 \mathrm{mg} \mathrm{mL}^{-1}$ of the standard diclofenac was prepared in a $50 \%$ methanol and diluted in concentrations between 10 to $80 \mu \mathrm{g} \mathrm{mL}^{-1}$ in $50 \%$ methanol, for calibration curve (Figure S4b, SI section). Measurements were made in triplicate and resulting chromatograms are presented in SI section (Figure S4a).

Portions of each powdered sample pharmaceutical formulations equivalent to $50 \mathrm{mg}$ of DCF that had been weighed previously were individually dissolved in a volume of 50\% methanol. The solutions were ultra-sonicated for $15 \mathrm{~min}$ and then made up to mark in $50 \mathrm{~mL}$ volumetric flask with mobile phase $\left(60 / 40 \mathrm{v} / \mathrm{v}, \mathrm{ACN} / \mathrm{H}_{2} \mathrm{O}\right)$. The solutions were centrifuged for $10 \mathrm{~min}$ at $4500 \mathrm{rpm}$. The resulting supernatants were filtered with $0.45 \mu \mathrm{m}$ membrane filter paper and $20 \mu \mathrm{L}$ of filtrate aliquot was introduced unto the column. Measurements were made in triplicate and resulting chromatograms are presented in SI section (Figure S4c).

Determination of DCF in synthetic urine by the standard addition method

Synthetic urine sample was prepared by dissolving $\mathrm{CaCl}_{2} \cdot \mathrm{H}_{2} \mathrm{O}, \mathrm{NaCl}, \mathrm{Na}_{2} \mathrm{SO}_{4}, \mathrm{KH}_{2} \mathrm{PO}_{4}, \mathrm{KCl}, \mathrm{NH}_{4} \mathrm{Cl}$, urea and creatinine in concentrations defined by Laube et al. ${ }^{38}$

The sample was intentionally spiked with aliquots of $15 \mu \mathrm{mol} \mathrm{L} \mathrm{L}^{-1}$ stock solution DCF in acetonitrile, resulting in $100 \mathrm{nmol} \mathrm{L}^{-1} \mathrm{DCF}$ work solutions.

\section{Results and Discussion}

\section{MIP and NIP particles characterization}

SEM images of MIP and NIP particles are presented in Figures 2a, 2c, 2e and Figures 2b, 2d, 2f, respectively. It is possible to observe that MIP particles presented more porosity and larger irregularity in sizes (Figures 2a, 2c, 2e) than the NIP ones (Figures 2b, 2d, 2f), that showed a more compact arrangement and more regular size distribution.

BET results agreed with SEM images in which MIP surface area $\left(314.8 \mathrm{~m}^{2} \mathrm{~g}^{-1}\right)$ was higher than NIP $\left(250.3 \mathrm{~m}^{2} \mathrm{~g}^{-1}\right)$. This increase of $25.6 \%$ in surface area could be caused by the presence of the template molecule in the polymer.

The two-dimensional images TEM for MIP-DCF and NIP-DCF are presented in Figures $3 \mathrm{a}$ and $3 \mathrm{~b}$. Three dimensional images in Figures $3 \mathrm{c}$ and $3 \mathrm{~d}$, respectively, were created using the software Matematica ${ }^{\circledR 39}$ confirming the higher porosity in the MIP.

The MIP-DCF particles presented small cavities of circular areas (Figure 3a). The particles NIP-DCF did not present such cavities (Figure 3b). The three-dimensional images presented in Figure 3 clearly demonstrate such difference.

\section{Voltammetric studies}

The behavior of DCF at both unmodified and modified composite electrodes containing different percentages of MIP 2.5, 5.0, 7.5 and $10 \%(\mathrm{~m} / \mathrm{m})$ was evaluated using DPASV in order to determine the best electrode composition for analytical purposes. Resulting voltammograms are presented in Figure 4. These curves presented the oxidation peak of DCF $\left(\mathrm{I}_{\mathrm{DCF}}\right)$ at $0.53 \mathrm{~V}$ (vs. SCE), which is displaced to higher potentials as the amount of MIP increases in the composite. Although similar DPASV profiles were observed for all modified electrodes, 

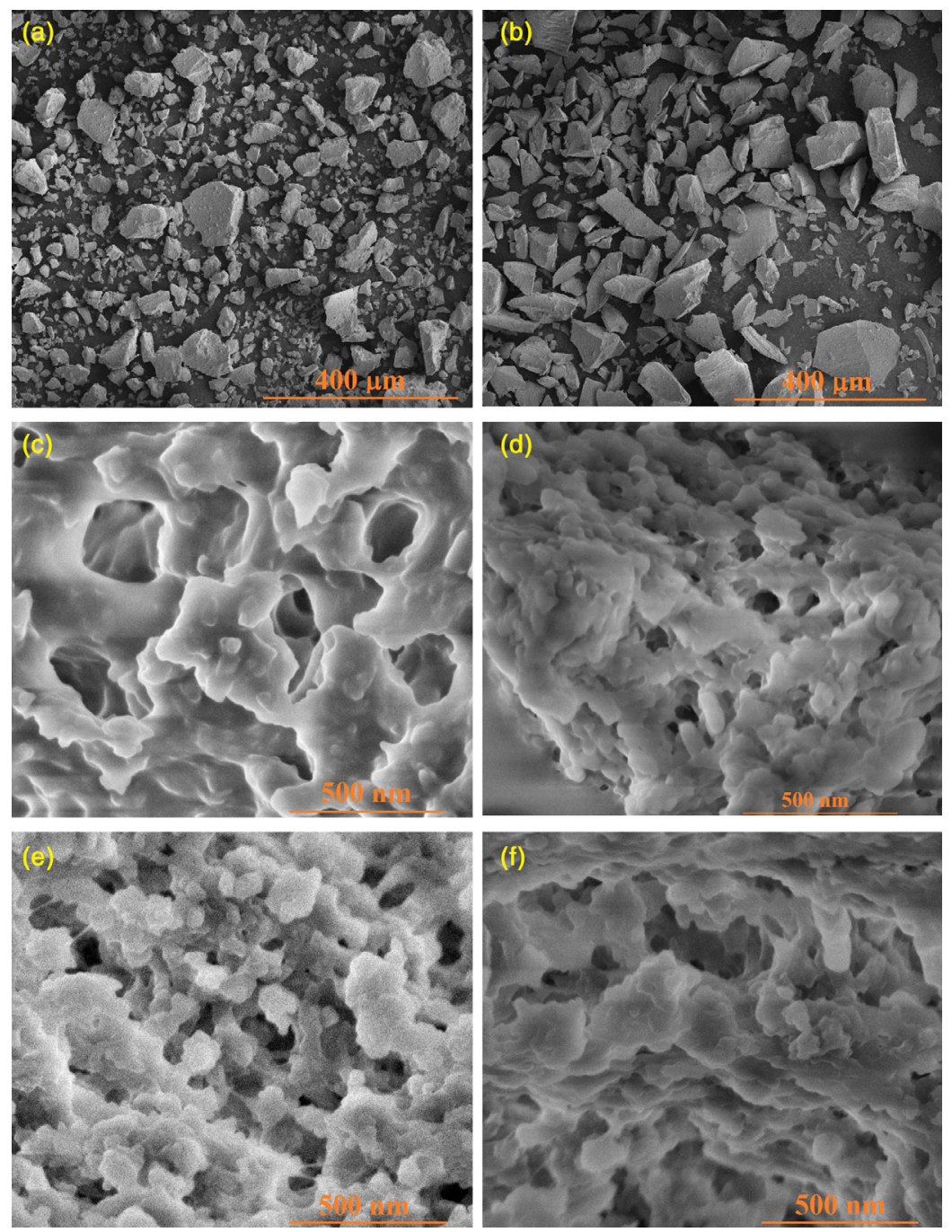

Figure 2. SEM of (a,c,e) MIP and (b,d,f) NIP particles. Magnifications (a,b) 250x and (c,d,e,f) 200,000x.
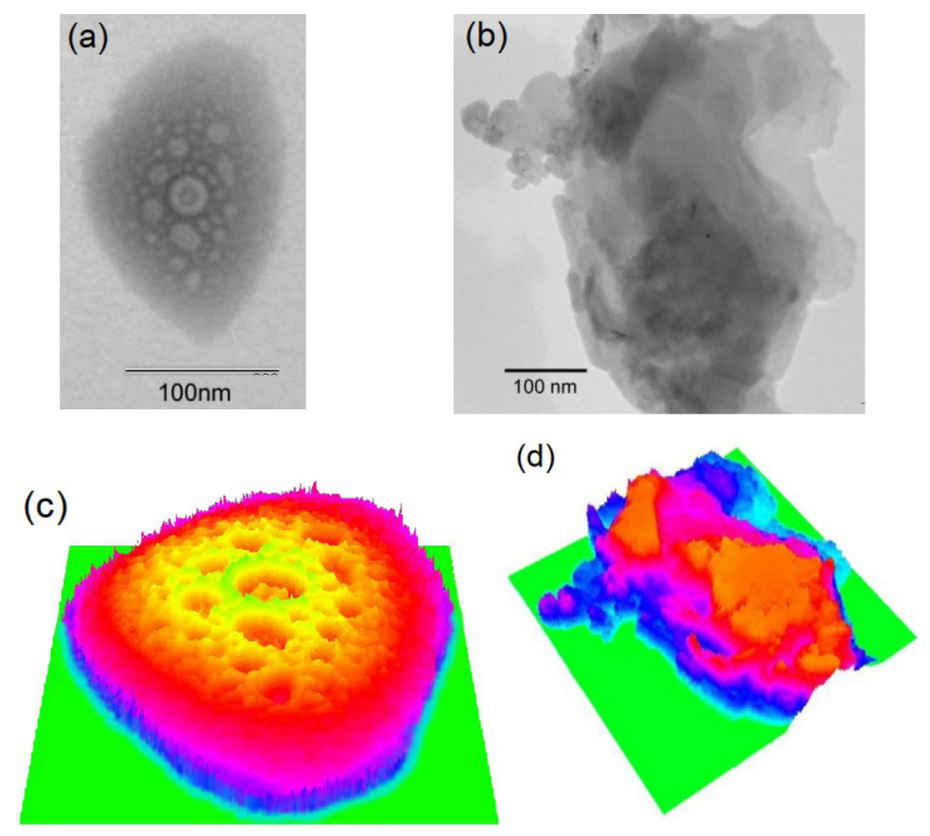

Figure 3. Two-dimensional TEM images of (a) MIP-DCF; (b) NIP-DCF and the respective three dimensional images (c) MIP-DCF and (d) NIP-DCF. 
peak currents decreased with increasing in MIP contents. Similar currents were observed for unmodified GPUE and GPUE with $10 \%$ MIP.

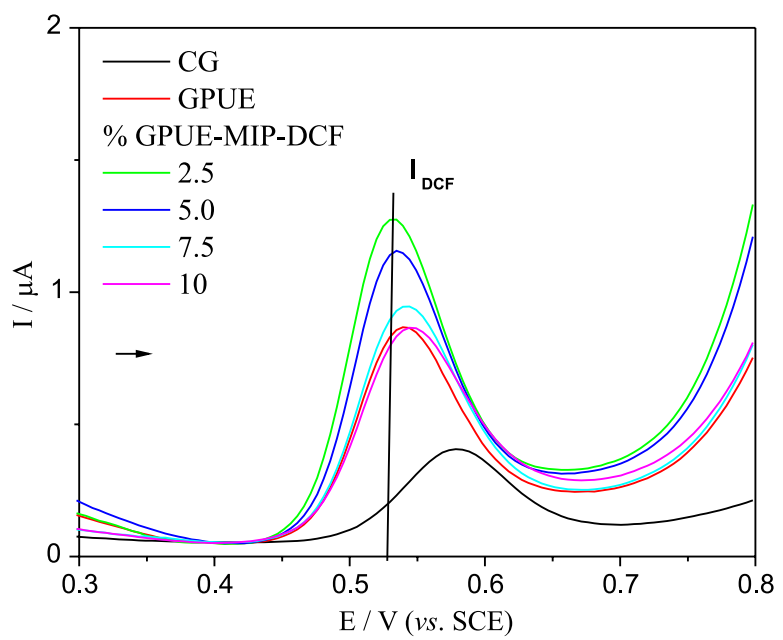

Figure 4. DPASV voltammograms obtained for DCF $20.0 \mu \mathrm{mol} \mathrm{L} \mathrm{L}^{-1}$ in phosphate buffer $\mathrm{pH} 7$, with $10 \% \mathrm{ACN}$, with glassy carbon (GC), unmodified GPUE and with 2.5, 5.0, 7.5 and 10\% GPUE-MIP-DCF, $\mathrm{a}=50 \mathrm{mV}$ and $\mathrm{v}=10 \mathrm{mV} \mathrm{s}^{-1}$.

This probably occurs due to the decrease in conducting graphite amount in the electrode material, and in the number of active sites available at electrode surface, that are substituted by the non-conducting methacrylic polymer. ${ }^{3}$ Thus, the $2.5 \%(\mathrm{~m} / \mathrm{m})$ was the MIP percentage chosen as better modifier amount in GPUE-MIP-DCF for further experiments.

Based on previous reports from Blanco-Lopez et al., ${ }^{28,29}$ the response of the GPUE-2.5-MIP-DCF sensor was evaluated in two supporting electrolytes: $25 \mathrm{mmol} \mathrm{L}^{-1}$ perchloric acid pH 2.0, with $10 \% \mathrm{ACN}(\mathrm{v} / \mathrm{v})$ and $0.1 \mathrm{~mol} \mathrm{~L}^{-1}$ phosphate solution with $10 \% \mathrm{ACN}(\mathrm{v} / \mathrm{v})$ in different $\mathrm{pH}$ values, from 2.0 to 7.0 , with resulting peak potential and currents presented in Table 1.

Actually the mechanisms of electrooxidation and electro degradation of DCF were reported by Cid-Cerón et al. ${ }^{40}$ and Zhao et al. ${ }^{41}$ respectively. Such mechanism involves the rupture in the secondary ammine with formation of 2,6-dichloroaniline and 2-(2-hydroxy-prop-2-enyl)phenol and is strongly dependent on the $\mathrm{pH}$ of the medium. In
$\mathrm{pH}$ lower than 4.7 (the reported $\mathrm{p} K_{\mathrm{a}}$ ) predominates the neutral species ${ }^{40}$ and in more basic medium the anionic form predominates. Zhao et al. ${ }^{41}$ detected several species from the exhaustive oxidation of the DCF. However, both agree that the protonated form is the more active. Blanco-Lopez et al. ${ }^{29}$ also reported that intense peak currents are observed at ca. $0.9 \mathrm{~V}$ in $0.1 \mathrm{~mol} \mathrm{~L}^{-1} \mathrm{HClO}_{4}$ and $0.7 \mathrm{~V}$ (vs. $\mathrm{Ag} / \mathrm{AgCl})$ in phosphate buffer $\mathrm{pH}$ 7. However, the peak current is almost $20 \%$ higher in acidic medium ${ }^{29}$ and even better when $0.025 \mathrm{~mol} \mathrm{~L}^{-1} \mathrm{HClO}_{4}$ in acetonitrile:water $(1: 9 \mathrm{v} / \mathrm{v})$ is used as supporting electrolyte, ${ }^{28}$ in agreement with our findings. Thus a $0.025 \mathrm{~mol} \mathrm{~L}^{-1} \mathrm{HClO}_{4}$ in acetonitrile:water $(1: 9 \mathrm{v} / \mathrm{v})$ was chosen for further studies.

Previous study ${ }^{42}$ regarding electrochemical impedance spectroscopy (EIS) performed on this material revealed that the presence of non-conductive modifiers as MIP and NIP just lowered the electroactive area, proportionally to the amount of modifier, once they are inner non-conductive species, without significant changes in the charge transfer parameters once the conductive material is still the same: graphite agglutinated by PU. For unmodified electrodes, EIS revealed an equivalent electrical circuit with a cell resistance, RW, in series with a parallel combination of a constant phase element, CPE, and a charge transfer resistance was used to fit the curves. In all cases, the $\mathrm{CPE}=\left\{\mathrm{C}(\mathrm{i} \omega)^{\alpha}\right\}^{-1}$ models a non-ideal capacitor, where $\mathrm{C}$ is the capacitance; $\mathrm{i}$ is the imaginary number; $\omega$ stands for the angular frequency and $\alpha$ accounts for the nonideal behavior of the capacitance. The CPE was found to be necessary because of the heterogeneous nature of the electrode, expressed through the exponent $\alpha$. A typical value of ca. 0.80 was obtained. The cell resistance RW was around $192 \mathrm{~W} \mathrm{~cm}^{2}$, a value expected for a composite electrode.

The electroactive surface area was determined by cyclic voltammetry, using $5 \mathrm{mmol} \mathrm{L}^{-1}$ hexacyanoferrate (II) in $0.5 \mathrm{~mol} \mathrm{~L}^{-1} \mathrm{KCl}$ and different potential scan rates (10-75 $\left.\mathrm{mV} \mathrm{s}^{-1}\right)$ : and applying Randles-Sevcik Equation considering the diffusion coefficient of hexacyanoferrate (II) as $7.7 \times 10^{-6} \mathrm{~cm}^{2} \mathrm{~s}^{-1}$ in $0.5 \mathrm{~mol} \mathrm{~L}^{-1} \mathrm{KCl}^{43}$ From a plot of peak current $v s$. scan rate, the electroactive area found

Table 1. Comparison between perchloric acid and phosphate solution

\begin{tabular}{|c|c|c|c|c|c|c|c|}
\hline \multirow[b]{3}{*}{$\mathrm{pH}$} & \multicolumn{7}{|c|}{ Supporting electrolyte } \\
\hline & \multirow{2}{*}{$\frac{\text { Perchloric acid }}{2.0}$} & \multicolumn{6}{|c|}{ Phosphate solution } \\
\hline & & 2.0 & 3.0 & 4.0 & 5.0 & 6.0 & 7.0 \\
\hline $\mathrm{E} / \mathrm{V}$ & 0.80 & 0.76 & 0.73 & 0.68 & 0.63 & 0.59 & 0.53 \\
\hline $\mathrm{I} / \mu \mathrm{A}$ & 7.75 & 5.72 & 3.34 & 3.36 & 1.20 & 1.38 & 0.98 \\
\hline
\end{tabular}

E: potential; I: current. 
was ca. $0.043 \mathrm{~cm}^{2}$, corresponding to $61 \%$ of the geometric area. When the MIP was incorporated into the composite material, the area resulted in ca. $18 \%$ lower.

In preliminary studies it was observed that a preconcentration step increased the response to the analyte, probably due to the accumulation of the analyte in the MIP particles.

So, an optimization of DPASV parameters was performed at GPUE-2.5-MIP-DCF and best results were obtained with $0.2 \mathrm{~V}(v s$. SCE) accumulation potential (Figure S1), $300 \mathrm{~s}$ of accumulation time (Figure S2), $50 \mathrm{mV}$ pulse amplitude and $10 \mathrm{mV} \mathrm{s}^{-1}$ scan rate (Figure S3).

\section{Analytical curve}

Once defined the DPASV conditions, voltammograms were obtained in DPASV for concentrations between 0.01 and $1.0 \mu \mathrm{mol} \mathrm{L} \mathrm{L}^{-1}$ DCF at GPUE, GPUE-2.5-MIP-DCF and GPUE-2.5-NIP composites (Figures 5a, 5b and 5c, respectively) for comparison, in order to determine the effect of the presence of the MIP on the sensitivity of the analytical response. Analytical curves are presented, with respective linear ranges as inset in Figure 5d.
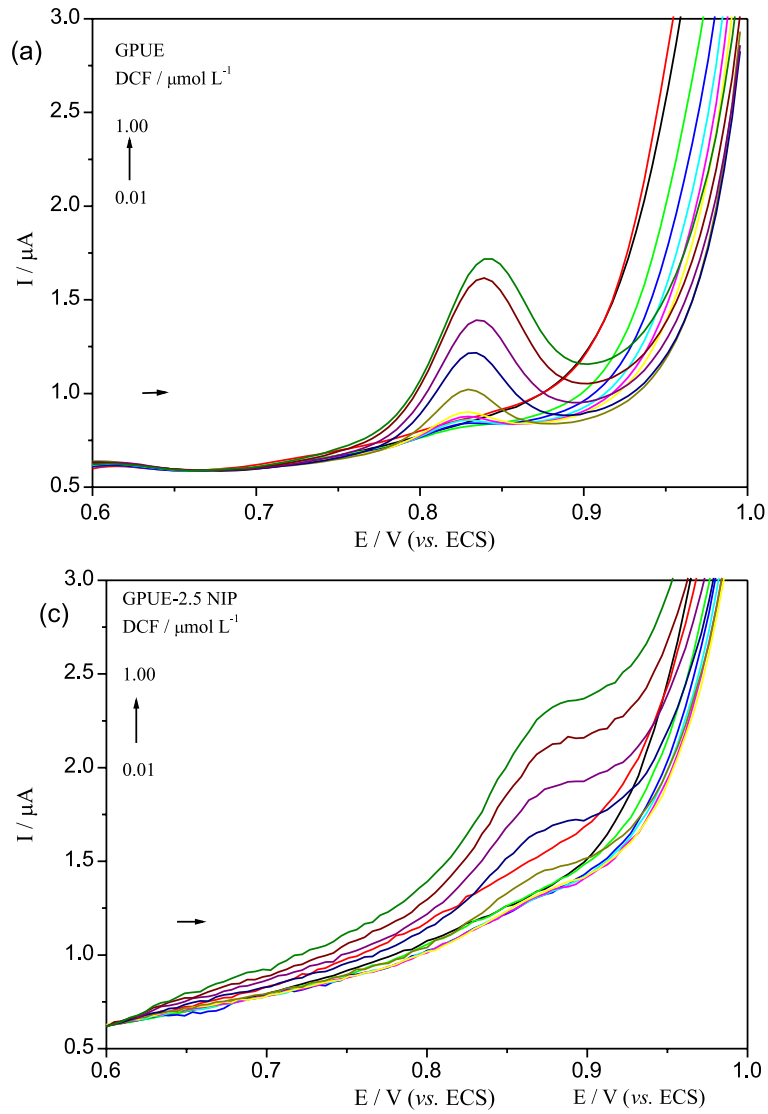

At GPUE-2.5-MIP-DCF composite, higher current intensity was obtained (>50\%), when compared to the GPUE and GPUE-2.5-NIP composites. From $0.2 \mu \mathrm{mol} \mathrm{L}^{-1}$ DCF, it was observed a distortion in the voltammetric profile, suggesting saturation of the active sites in electrodes surfaces. ${ }^{3,44}$

Actually the presence of MIPs promotes an accumulation of analyte on the electrode surface due to their specific cavities. On the other hand, as methacrylic polymers are non-conductive species, they replace conductive spots on the same surface. Thus, there is here a competition between accumulation $v s$. conductive spots available in the composite surface. When lower MIP amounts are introduced into the composite it seems that the accumulation effect is higher than the replacement of the conductive material. As the MIP amount increases the opposite effect takes place, and it seems that the replacement effect becomes more significant than the accumulation, resulting in current decrease.

It is common that the methacrylic polymer itself can interact with the analyte during the accumulation step, once it has pendant functional groups that are the same as those in the imprinted polymer. However, as it does not have cavities molded during the imprinting process it is not as active as
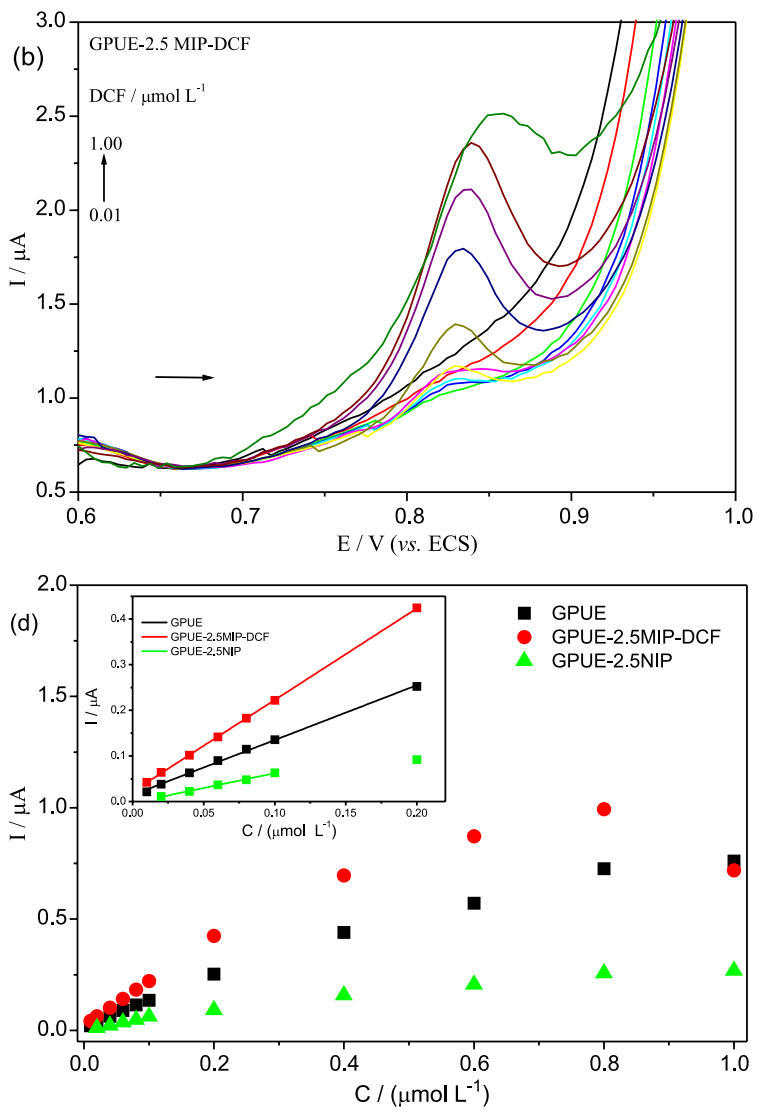

Figure 5. DPASV voltammograms at (a) GPUE; (b) GPUE-2.5-MIP-DCF and (c) GPUE-2.5-NIP composites, in 25 mmol L-1 perchloric acid with $10 \%$ ACN and DCF concentrations of $0.010,0.020,0.040,0.060,0.080,0.10,0.20,0.40,0.60,0.80$ and $1.0 \mu \mathrm{mol} \mathrm{L}^{-1}, \mathrm{t}_{\mathrm{acc}}=300 \mathrm{~s}, \mathrm{E}_{\mathrm{acc}}=0.2 \mathrm{~V}, \mathrm{a}=50 \mathrm{mV}$, $\mathrm{v}=10 \mathrm{mV} \mathrm{s}^{-1} ;(\mathrm{d})$ analytical curves and linear ranges in the inset. 
the MIP. However, as the non-conductive acrylic polymer is introduced into the composite it replaces conducting graphite in the surface of the electrodes, resulting in lower peak current regarding the unmodified GPUE.

Table 2 presents analytical features regarding data from curves in Figure 5.

The sensitivity of the GPUE-2.5-MIP-DCF was twice higher than that for unmodified GPUE and three times higher than that for the electrode modified with the NIP.

The presence of MIP in the GPUE-2.5-MIP-DCF allowed the interaction of the DCF with the functional groups present in the MIP cavities increasing the sensitivity. Once the GPUE-2.5-NIP composite does not present these cavities, it was observed lower current intensity, associated to the occupation of conductive sites of the graphite by the non-conducting modifier, besides not favoring the preconcentration of the analyte.
The current intensity at GPUE was higher than GPUE2.5-NIP due to higher amount of conductor material in the surface and consequently higher active area.

Comparing to literature, the limit of detection (LOD) obtained at GPUE-2.5-MIP-DCF was lower than those presented in Table 3, without need for surface renovation.

In the Blanco-López et al. ${ }^{28,29}$ papers and in this work, MIPs were prepared using the same reagents and methodology, including template extraction which was made by washing with methanol/acetic acid. However, Blanco-López et al. ${ }^{29}$ incorporated MIPs on the electrode surface and the template removal was made by immersing the electrode in the stirred solution. Mostafavi et al. ${ }^{31}$ prepared MIPs using different reagents and methodology, comparing to the first authors. In this paper, the template was extracted with deionized water under ultrasonic irradiation. Seguro et al..$^{32}$ and Malekzadeh et al. ${ }^{33}$ prepared

Table 2. Analytical features for the different electrodes

\begin{tabular}{lcccc}
\hline Electrode & Linear range $/(\mu \mathrm{mol} \mathrm{L}-1)$ & $\begin{array}{c}\text { Linear correlation } \\
\text { coefficient }(\mathrm{R})\end{array}$ & $\begin{array}{c}\text { Sensitivity } /\left(\mu \mathrm{A} \mu \mathrm{mol}^{-1} \mathrm{~L}\right) \\
\mathrm{LOD}^{\mathrm{a}} /(\mathrm{nmol} \mathrm{L})\end{array}$ & 5.31 \\
GPUE & $0.010-0.20$ & 0.997 & 1.20 & 0.990 \\
GPUE-2.5-MIP-DCF & $0.010-0.20$ & 0.999 & 2.01 & 6.13 \\
\hline
\end{tabular}

aODs were calculated according to the definition from Long and Winefordner, ${ }^{45} \mathrm{LOD}=3 \mathrm{Sd}_{\mathrm{A}} / \mathrm{b}$, in which $\mathrm{Sd}_{\mathrm{A}}$ is blank deviation and $\mathrm{b}$ is the slope. LOD: limit of detection; GPUE: graphite-polyurethane composite electrode; GPUE-2.5-MIP-DCF: GPUE-2.5-molecularly imprinted polymer synthesis using diclofenac; GPUE-2.5-NIP: GPUE-2.5-non-imprinted polymer.

Table 3. MIP formation and analytical features for some electrodes modified with MIP in the DCF voltammetric determination

\begin{tabular}{|c|c|c|c|c|c|c|c|}
\hline Electrode & $\begin{array}{l}\text { Reagents used in } \\
\text { MIP synthesis }\end{array}$ & $\begin{array}{l}\text { Formation of the MIP } \\
\text { (experimental conditions) }\end{array}$ & Technique & $\begin{array}{l}\text { Sensibility / } \\
\left(\mathrm{A} \mu \mathrm{mol}^{-1} \mathrm{~L}\right)\end{array}$ & $\begin{array}{l}\text { Linear region / } \\
\left.\quad(\mu \mathrm{mol} \mathrm{L})^{-1}\right)\end{array}$ & $\begin{array}{c}\mathrm{LOD} / \\
\left(\mathrm{mol} \mathrm{L}^{-1}\right)\end{array}$ & Reference \\
\hline $\begin{array}{l}\text { Polytetrafluoroethylene- } \\
\text { graphite, epoxy-graphite } \\
\text { and epoxy-carbon black }\end{array}$ & $\begin{array}{l}\text { MAA, EGDMA, } \\
\text { AIBN, ACN }\end{array}$ & $\begin{array}{l}\text { thermic }\left(60^{\circ} \mathrm{C}\right) ; \\
\text { MIP incorporated to the } \\
\text { electrode body }\end{array}$ & DPV & $5 \times 10^{-7}$ & $0.06-1.0$ & $5 \times 10^{-8}$ & 28 \\
\hline Glassy carbon (GC) & $\begin{array}{l}\text { MAA, EGDMA, } \\
\text { AIBN, ACN }\end{array}$ & $\begin{array}{c}60{ }^{\circ} \mathrm{C} ; \\
\text { film MIP on electrode } \\
\text { surface }\end{array}$ & DPV & ni & ni & ni & 29 \\
\hline Carbon paste & $\begin{array}{c}\text { aniline, } \\
\text { triphenylamine, } \\
\text { ammonium } \\
\text { persulfate, water, } \\
\text { ethanol }\end{array}$ & $\begin{array}{l}\text { ultrasonic irradiation; } \\
\text { MIP incorporated to the } \\
\text { electrode body }\end{array}$ & DPV & $1.75 \times 10^{-6}$ & $16.9-270$ & $3.71 \times 10^{-6}$ & 31 \\
\hline Screen printed & - & $\begin{array}{l}\text { electropolymerization; } \\
\text { MIP on electrode surface }\end{array}$ & DPV & $3.78 \times 10^{-7}$ & $0.1-10$ & $70 \times 10^{-9}$ & 32 \\
\hline $\mathrm{Zr}-\mathrm{MOF} / \mathrm{GC}$ & $\begin{array}{l}p \text {-amino benzoic } \\
\text { acid }\end{array}$ & $\begin{array}{l}\text { electropolymerization; } \\
\text { film MIP on electrode } \\
\text { surface }\end{array}$ & DPV & ni & $6.5-1500$ & $0.1 \times 10^{-6}$ & 33 \\
\hline This work & $\begin{array}{l}\text { MAA, EGDMA, } \\
\text { AIBN, ACN }\end{array}$ & $\begin{array}{l}\text { thermic } 50^{\circ} \mathrm{C} \text {; } \\
\text { MIP incorporated to the } \\
\text { electrode body }\end{array}$ & DPASV & $2.01 \times 10^{-6}$ & $0.01-0.2$ & $9.9 \times 10^{-10}$ & - \\
\hline
\end{tabular}

MIP: molecularly imprinted polymer; LOD: limit of detection; MAA: methacrylic acid; EGDMA: ethyleneglycol dimetacrylate; AIBN: azobisisobutyronitrile; ACN: acetonitrile; DPV: differential pulse voltammetry; ni: not informed; MOF: metal-organic framework; DPASV: differential pulse anodic stripping voltammetry. 
MIPs by electropolymerization using cyclic voltammetric, without the need of crosslinking agent and radical initiator. Monomer was used only in the second case. ${ }^{33} \mathrm{DCF}$ molecules were removed using methanol and sodium hydroxide by Seguro et al. ${ }^{32}$ and methanol/acetic acid on a magnetic stir by Malekzadeh et al. . $^{33}$

Comparing the results presented in Table 3, using different electrodes modified with MIP, it can be observed that higher sensitivity and lower limit of detection were obtained in the present work.

\section{Determination of DCF in pharmaceutical formulations and synthetic urine}

DCF was determined in commercial pharmaceutical formulations as well as in synthetic urine, under the conditions optimized for DPASV at GPUE-2.5-MIP-DCF composite electrode by the standard addition method.

Successive aliquots of DCF standard solution were added to the pharmaceutical samples containing $100 \mathrm{nmol} \mathrm{L}^{-1}$ DCF in perchloric acid pH 2.0 with $10 \% \mathrm{ACN}$, in order to obtain concentrations of 20,40 and $60 \mathrm{nmol} \mathrm{L}^{-1}$ DCF. The synthetic urine sample was spiked with $100 \mathrm{nmol} \mathrm{L}^{-1} \mathrm{DCF}$.

No significant interference from excipients present in the pharmaceutical samples was observed during the DCF analysis.

Table 4 presents the results of the determination of DCF in commercial pharmaceutical samples at GPUE-2.5-MIPDCF when compared to those from HPLC comparative procedure.

The results showed the efficiency of the GPUE-2.5-MIP-DCF composite in the DCF determination in pharmaceutical commercial samples and synthetic urine once they agreed with the comparative procedure within 95\% confidence level, according to Student's $t$-test. Recoveries are also presented in Table 4 and suggested few interference from the concomitants in the pharmaceutical and synthetic urine samples.

\section{Selectivity evaluation of the GPUE-2.5-MIP-DCF}

The main reason for using an MIP as an electrode modifier is the possibility of improving selectivity. In this case, selectivity of the GPUE-MIP regarding to DCF was evaluated in interference tests using meclofenamic acid (AMCFN) and mefenamic acid (AMFN), substances whose chemical structures are similar to the DFC, and contain the same functional groups also present in the structure of DCF. These potential interferents were chosen also based on their biological relevance. The structural formulae of DCF and the potential interferents AMCFN and AMFN used in selectivity studies are illustrated in Figure 6.<smiles>Cc1ccc(Cl)c(Nc2ccccc2C(=O)O[Na])c1Cl</smiles>

(a)<smiles>Cc1cccc(Nc2ccccc2C(=O)O)c1C</smiles>

(b)
Figure 6. Chemical structure of (a) AMCFN and (b) AMFN.

Table 5 summarizes the results of selectivity test in solutions containing $150 \mathrm{nmol} \mathrm{L}^{-1}$ DCF in $25 \mathrm{mmol} \mathrm{L}^{-1}$ perchloric acid pH 2.0 with $10 \% \mathrm{ACN}$ in the presence of 75,150 and $300 \mathrm{nmol} \mathrm{L}^{-1}$ of the interferent, in DPASV.

When $150 \mathrm{nmol} \mathrm{L}^{-1}$ of DCF were determined in the presence of 75, 150 and $300 \mathrm{nmol} \mathrm{L}{ }^{-1}$ of AMCFN, interferences occurred in all cases, however, in minor percentage for the GPUE-2.5-MIP-DCF electrode, when compared to the electrode GPUE-2.5-NIP.

These results suggest that, even with interference, the MIP provided a higher degree of discrimination between the analyte and the interfering when compared to the NIP, even considering the close structural similarity between the DCF and the AMCFN. Therefore, the EGPU modified with MIP has its selectivity increased in relation to the electrode modified with NIP, which demonstrates that this characteristic can be enhanced, in this case.

Table 4. Determination of DCF in commercial pharmaceutial samples and synthetic urine at GPUE-2.5-MIP-DCF in DPASV, using the conditions optimized in this work

\begin{tabular}{|c|c|c|c|c|c|c|c|}
\hline \multirow{2}{*}{ Sample } & \multicolumn{3}{|c|}{ Content per tablet / mg } & \multicolumn{3}{|c|}{ Relative error / \% } & \multirow{2}{*}{ Recoveries } \\
\hline & Labeled & DPASV & HPLC & $\mathrm{E}_{1}$ & $\mathrm{E}_{2}$ & $E_{3}$ & \\
\hline 1 & 50.0 & $49 \pm 5$ & $48 \pm 1$ & -2.1 & -3.8 & 1.5 & $101 \pm 3$ \\
\hline 2 & 50.0 & $47.2 \pm 0.3$ & $50 \pm 2$ & -5.7 & -1.3 & -4.6 & $102 \pm 3$ \\
\hline 3 & 50.0 & $50 \pm 2$ & $50 \pm 1$ & -0.5 & -0.6 & 0.1 & $102 \pm 3$ \\
\hline Synthetic urine & - & - & - & - & - & - & $101 \pm 2$ \\
\hline
\end{tabular}

DPASV: differential pulse anodic stripping voltammetry; HPLC: high-performance liquid chromatography; $\mathrm{E}_{1}=\mathrm{DPASV} v s$. labeled: [(DPASV - labeled) $/$ labeled $] \times 100 \% ; \mathrm{E}_{2}=$ HPLC $v s$. labeled: $((\mathrm{HPLC}-$ labeled $) /$ labeled $) \times 100 \% ; \mathrm{E}_{3}=\mathrm{DPASV} v s$. HPLC: $((\mathrm{DPASV}-\mathrm{HPLC}) / \mathrm{HPLC}) \times$ $100 \%$. 
Table 5. Interference of meclofenamic acid

\begin{tabular}{|c|c|c|c|c|c|c|c|}
\hline \multirow{3}{*}{$\begin{array}{l}\mathrm{C}_{\mathrm{DCF}}: \mathrm{C}_{\mathrm{AMCFN}} / \\
\left.(\mathrm{nmol} \mathrm{L})^{-1}\right)\end{array}$} & \multicolumn{7}{|c|}{ Interference / \% } \\
\hline & \multicolumn{4}{|c|}{ GPUE-2.5-MIP-DCF } & \multicolumn{3}{|c|}{ GPUE-2.5-NIP } \\
\hline & $\mathrm{I}_{\mathrm{p}} / \mathrm{nA}$ & $\mathrm{I}_{\mathrm{p}} / \%$ & Observed & Expected & $\mathrm{I}_{\mathrm{p}} / \mathrm{nA}$ & $\mathrm{I}_{\mathrm{p}} / \%$ & Observed \\
\hline $150: 0$ & 173 & 100 & - & - & 29.6 & 100 & - \\
\hline $150: 75$ & 196 & 113 & 13.3 & 50 & 42.7 & 144 & 44.3 \\
\hline $150: 150$ & 180 & 104 & 4.00 & 100 & 37.9 & 128 & 28.0 \\
\hline $150: 300$ & 177 & 102 & 2.30 & 200 & 31.5 & 106 & 6.40 \\
\hline
\end{tabular}

GPUE-2.5-MIP-DCF: GPUE-2.5-molecularly imprinted polymer synthesis using diclofenac; GPUE-2.5-NIP: GPUE-2.5-non-imprinted polymer; $\mathrm{C}_{\mathrm{DCF}}: \mathrm{C}_{\mathrm{AMCFN}}$ : concentration of diclofenac:concentration of meclofenamic acid; $\mathrm{I}_{\mathrm{p}}$ : peak current.

Table 6. Interference of mefenamic acid

\begin{tabular}{|c|c|c|c|c|c|c|c|}
\hline \multirow{3}{*}{$\begin{array}{l}\mathrm{C}_{\mathrm{DCF}}: \mathrm{C}_{\mathrm{AMFN}} / \\
\left(\mathrm{nmol} \mathrm{L}{ }^{-1}\right)\end{array}$} & \multicolumn{7}{|c|}{ Interference / \% } \\
\hline & \multicolumn{3}{|c|}{ GPUE-2.5-MIP-DCF } & \multirow{2}{*}{$\begin{array}{c}\text { Theoretical } \\
\text { Expected }\end{array}$} & \multicolumn{3}{|c|}{ GPUE-2.5-NIP } \\
\hline & $\mathrm{I}_{\mathrm{p}} / \mathrm{nA}$ & $\mathrm{I}_{\mathrm{p}} / \%$ & Observed & & $\mathrm{I}_{\mathrm{p}} / \mathrm{nA}$ & $\mathrm{I}_{\mathrm{p}} / \%$ & Observed \\
\hline $150: 0$ & 160 & 100 & - & - & 29.4 & 100 & - \\
\hline $150: 75$ & 150 & 93.8 & -6.20 & 50 & 22.7 & 77.2 & -22.8 \\
\hline $150: 150$ & 285 & 178 & 77.6 & 100 & 97.3 & 331 & 231 \\
\hline $150: 300$ & 678 & 422 & 323 & 200 & 233 & 793 & 693 \\
\hline
\end{tabular}

GPUE-2.5-MIP-DCF: GPUE-2.5-molecularly imprinted polymer synthesis using diclofenac; GPUE-2.5-NIP: GPUE-2.5-non-imprinted polymer; $\mathrm{C}_{\mathrm{DCF}}$ : $\mathrm{C}_{\mathrm{AMFN}}$ : concentration of diclofenac: concentration of mefenamic acid; $\mathrm{I}_{\mathrm{p}}$ : peak current.

Table 6 summarizes the interference results for AMFN in DCF solutions.

The same procedure was performed with the interfering AMFN. In this case, despite the greater interference observed in both electrodes, the dispositive containing MIP presented better performance than the electrode containing NIP, in relation to the selectivity.

The relatively high interference was attributed to the coincidence in the peak oxidation potentials of the analyte and of the interferent. However, the smaller interference in the case of the electrode modified with MIP showed that the modifier is capable of promoting discrimination between analyte and interferent with higher efficiency than that modified with NIP, despite the structural similarity of the two species.

Thus, it is demonstrated that not only the conformational effect presents an important role in selectivity, but also the voltammetric response related to the oxidation-reduction processes of the functional groups present in the interferent, can affect the selectivity.

As it was previously observed for folic acid, ${ }^{4}$ not only the size of the template molecule, but also their functional groups cause interference in the electrode modified with MIP.

\section{Conclusions}

A methacrylate polymer molecularly imprinted with the anti-inflammatory drug diclofenac as a template was prepared. After removing the template molecule, the MIP was characterized regarding morphologic characteristics and surface area. SEM and BET results revealed that after removing the template molecule a higher porosity was generated on the MIPs particles surface when compared with a similar non-imprinted polymer (NIP). Two-dimensional TEM images were used to create a computational 3-D image of MIP and NIP particles, confirming the generation of pores and cavities in the MIP particles.

MIP and NIP were used as modifiers in graphite polyurethane composite electrodes, used in the voltametric determination of diclofenac with significant improvement in the performance of the resulting device when using MIP in a differential pulse voltammetric procedure after accumulation of the analyte in the electrode surface, under optimized solution composition and voltametric conditions. An acidic acetonitrile-water solution was used once it presented higher peak currents, than other medium evaluated.

The presence of an appropriate amount of modifier allowed finding a balance between accumulation of the analyte and loss of active sites in the electrode surface when non-conducting polymer is used as modifier.

Under the optimized conditions a limit of detection at sub-nmol $\mathrm{L}^{-1}$ level could be reached using the GPUE-2.5-MIP-DCF that was successfully used in the determination of the analyte in commercial pharmaceutical 
formulations and a synthetic urine, with results in statistical agreement with the reference chromatographic procedure.

The resulting device is robust and could be used during at least 6 months without significant loss in the voltammetric signal and presented a better performance when compared to other voltammetric electrodes modified with imprinted polymers with diclofenac as a template.

Regarding selectivity, the GPUE-2.5-MIP-DCF electrode presented a capability of discriminating the DCF signal even in the presence of potential interferents with strictly similar structure as mefenamic and meclofenamic acids, although due to the presence of same functional groups and chemical structure, interferences could not be fully avoided.

Thus, after all these investigations it is possible to conclude that the proposed work resulted in a robust electrode and a powerful tool for DCF analysis in pharmaceutical formulations and biologic fluids in a sensitive and relatively selective procedure.

\section{Supplementary Information}

Supplementary information is available free of charge at http://jbcs.sbq.org.br as PDF file.

\section{Acknowledgments}

The authors are grateful to the Brazilian agencies FAPESP and CNPq (for A. V. P. doctoral fellowship) as well as PROCONTES/USP program for support.

\section{References}

1. Pauling, L.; J. Am. Chem. Soc. 1940, 62, 2643.

2. Tarley, C. R. T.; Sotomayor, M. D. P. T.; Kubota, L. T.; Quim. Nova 2005, 28, 1076.

3. Cervini, P.; Cavalheiro, E. T. G.; Anal. Lett. 2009, 42, 1940.

4. Pereira, A. V.; Cervini, P.; Cavalheiro, E. T. G.; Anal. Methods 2014, 6, 6658.

5. Clarindo, E. J. S.; Viana, R. B.; Cervini, P.; Silva, A. B. F.; Cavalheiro, E. T. G.; Anal. Lett. 2020, 53, 1932.

6. Haupt, K.; Mosbach, K.; Chem. Rev. 2000, 100, 2495.

7. Piletsky, S. A.; Alcock, S.; Turner, A. P. F.; Trends Biotechnol. 2001, 19, 9.

8. Cervini, P.; Cavalheiro, E. T. G.; Anal. Lett. 2012, 45, 297.

9. Todd, P. A.; Sorkin, E. M.; Drugs 1998, 35, 244.

10. Garcia Filho, R. J.; Korukian, M.; dos Santos, F. P. E.; Viola, D. M.; Puertas, E. B.; Acta Ortop. Bras. 2006, 14, 11.

11. Geller, M.; Krymchantowski, A. V.; Steinbruch, M.; Cunha, K. S.; Ribeiro, M. G.; Oliveira, L.; Ozeri, D.; Daher, J. P. L.; Rev. Soc. Bras. Med. 2012, 10, 29.
12. Chen, G.; Den Braver, M. W.; Van Gestel, C. A. M.; Van Straalen, N. M.; Roelofs, D.; Environ. Pollut. 2015, 199, 253.

13. Carballa, M.; Omil,F.; Lema,J. M.;Llompart, M.; García-Jares, C.; Rodríguez, I.; Gómez, M.; Ternes, T.; Water Res. 2004, 38, 2918.

14. Thanhmingliana, T. D.; Tiwardi, D.; Chem. Eng. J. 2015, 263, 364.

15. Hübner, U.; Jekel, M.; Water Sci. Technol. 2013, 68, 1665.

16. Wang, Y.; Liu, H.; Liu, G.; Xie, Y.; Gao, S.; Sci. Total Environ. 2015, 506-507, 252.

17. Quintana, J. B.; Carpinteiro, J.; Rodríguez, I.; Compr. Anal. Chem. 2007, 50, 185.

18. Ji, W.; Zhang, J.; J. Chromatogr. A 2000, 868, 101.

19. Hafsa, D.; Chanda, S.; Prabhu, P. J.; J. Chem. 2011, 8, 1620.

20. Heydari, R.; Shamsipur, M.; Naleini, N.; AAPS PharmSciTech 2013, 14, 764.

21. Lucas, F. W.; Mascaro, L. H.; Fill, T. P.; Rodrigues-Filho, E.; Franco-Junior, E.; Homem-de-Mello, P.; de Lima-Neto, P.; Correia, A. N.; Langmuir 2014, 30, 5645.

22. Lhos, M.; Remes, A.; Manea, F.; J. Environ. Protect. Ecol. 2012, 13, 2096.

23. Goyal, R. N.; Chatterjee, S.; Agrawal, B.; Sens. Actuators, B 2010, 145, 743.

24. Karuppiah, C.; Cheemalapati, S.; Chen, S. M.; Palanisamy, S.; Ionics 2014, 21, 231.

25. Yang, X.; Wang, F.; Hu, S.; Mater. Sci. Eng., C 2008, 28, 188.

26. Damiri, S.; Oskoei, Y. M.; Fouladgar, M.; J. Exp. Nanosci. 2016, $11,1384$.

27. Jahani, P. M. J.; Mohammadi, S. Z.; Khodabakhshzadeh, A.; Cha, J. H.; Asl, M. S.; Shokouhimehr, M.; Zhang, K.; Le, Q. V.; Peng, W.; Int. J. Electrochem. Sci. 2020, 15, 9037.

28. Blanco-López, M. C.; Fernández-Llano, L.; Miranda-Ordieres, A. J.; Tuñón-Blanco, P.; Anal. Lett. 2004, 37, 915.

29. Blanco-López, M. C.; Lobo-Castañón, M. J.; Miranda-Ordieres, A. J.; Tuñón-Blanco, P.; Anal. Bioanal. Chem. 2003, 377, 257.

30. Al-Bayati, Y. K.; Al-Safi, A. J.; Baghdad Sci. J. 2018, 15, 63.

31. Mostafavi, M. F.; Yaftian, M. R.; Piri, F.; Shayani-Jam, H.; Biosens. Bioelectron. 2018, 122, 160.

32. Seguro, I.; Pacheco, J. G.; Matos, C. D.; Sensors 2021, 21, 1975.

33. Malekzadeh, M.; Mohadesi, A.; Mohammad, A.; Mehdi, R.; Anal. Bioanal. Electrochem. 2020, 12, 402.

34. Tarley, C. R. T.; Sotomayor, M. D. P. T.; Kubota, L. T.; Quim. Nova 2005, 28, 1076.

35. Mendes, R. K.; Claro-Neto, S.; Cavalheiro, E. T. G.; Talanta 2002, 57, 909.

36. Fontes, M.; Farmacopéia Brasileira, $4^{\text {th }}$ ed.; Atheneu Editora: São Paulo, 1988.

37. Kirim, R. A.; Mustapha, K. B.; Isimi, C. Y.; Ache, T.; Sadiq, A.; Galadima, I. H.; Gamaniel, K. S.; Afr. J. Pharm. Pharmacol. 2014, 8, 924.

38. Laube, N.; Mohr, B.; Hesse, A.; J. Cryst. Growth 2001, 233, 367. 
39. https://www.wolfram.com/mathematica-student-edition/, accessed in October 2021.

40. Cid-Cerón, M. M.; Guzmán-Hernández, D. S.; Ramírez-Silva, M. T.; Galano, A.; Romero-Romo, M.; Palomar-Pardavé, M.; Electrochim. Acta 2016, 199, 92.

41. Zhao, X.; Yining, H.; Huijuan, L.; Zhimin, Q.; Jiuhui, Q.; Electrochim. Acta 2009, 54, 4172.

42. Semaan, F. S.; Pinto, E. M.; Cavalheiro, E. T. G.; Brett, C. M. A.; Electroanalysis 2008, 20, 2287.
43. Stackelberg, M.; Pilgram, M.; Toome, V.; Electrochemistry 1953, 57, 342.

44. Pupin, R. R.; Monteiro, G. C.; Foguel, M. V.; Bolzani, V. S.; Pividori, M. I.; Sotomayor, M. D. P. T. In Molecularly Imprinted Polymers (MIPs): Challenges, Uses and Prospects, $1^{\text {st }}$ ed.; Hauppauge: Nova Science Publishers, 2016, p. 43-118.

45. Long, G. L.; Winefordner, J. D.; Anal. Chem. 1983, 55, 712A.

Submitted: June 2, 2021

Published online: October 6, 2021 